\title{
Celestina: Documento bibliográfico (suplemento número 34)
}

\author{
Devid Paolini \\ The City College of New York
}

[Querría expresar mi gratitud a todos los amigos y colegas que me han informado acerca de artículos, reseñas, investigaciones in fieri sobre $L C$, o han contestado a mis correos/peticiones enviándome copia de sus trabajos. Me refiero, en particular, a: José Antonio Bernaldo del Quirós, Carlos Heusch, Santiago López-Ríos y al siempre amable Joseph T. Snow, que también ha reseñado una entrada (que indico al final con la sigla: JTS). Como ya he tenido la ocasión de decir, espero que esta lista crezca con el pasar del tiempo porque "los bienes, si no son comunicados, no son bienes». Los que quieran ponerse en contacto conmigo podrán hacerlo en la siguiente dirección de correo electrónico: dpaolini@ccny.cuny.edu Muchísimas gracias, DP]

2221. ÁLVAREZ-MORENO, Raúl, "Celestina o el intercambio simbólico: algunas consideraciones sobre la lógica social del consumo en la Tragicomedia de Calisto y Melibea», eHumanista 19 (2011), 1-19.

En el artículo se ofrece un análisis de $L C$ desde el punto de vista de la teoría económica. El consumo y la producción, que en la obra se presentan bajo la forma de deseo, goce, posesión e intercambio, nos pueden dar una clave más de interpretación de la obra.

2222. ÁLVAREZ-MORENO, Raúl, "Propiedad y dominium en Castilla a finales del siglo Xv: Celestina como civitas non recte instituta», Celestinesca 35 (2011), 9-42.

El estudioso subraya la importancia del principio de la propiedad y su transgresión como motivo principal de contraste para comprender 
buena parte de los conflictos presentes en la obra. Los personajes de $L C$, interesados solamente en sí mismos, irían en contra de los ideales socio-políticos de los Reyes Católicos y representarían así una civitas non recte instituta.

2223. BERNALDO DE QUIRÓS, José Antonio, «Efectos provocados por las adiciones primeras en la Comedia de Calisto y Melibea. Una clasificación», Etiópicas 8 (2012), 172-199.

La premisa de trabajo es que los autos I-XIV son del primer autor anónimo y aquí evalúa las adiciones de Fernando de Rojas a estos autos. En fin, se trata de clasificar unas tres docenas de adiciones, catalog dolas según el tipo de deterioro que le suponen al texto «original». Por ejemplo, hay adiciones que alteran la sintaxis, otras que rompen con el juego dramático, otras que son repeticiones o transposiciones, o instancias de innecesario amontonamiento de vocablos, instancias de contradicciones, ruptura de la organización interna del texto, y otras. Cada una se presenta y se analiza con cuidado. [JTS]

2224. BERNALDO DE QUIRÓS, José Antonio, «Sobre una presunta Celestina en catalán», en El Norte de Castilla, 3 de septiembre de 2012, 36-37.

Artículo periodístico donde el estudioso expone sus dudas acerca de las hipótesis de Manuel Civera que cree que LC se imprimió originalmente en catalán, su autor fue Joan Martorell y la acción ocurrió en Sagunto. Véanse, para más información sobre el asunto, el artículo dedicado a Civera y publicado el 25 de julio de 2012 en levante-emv. com y las breves reflexiones de Albert Cuadrado (28 de agosto de 2012) sobre la cuestión en la página web del Institut d'Estudis Valencians [http://www.inev.org/; fecha de consulta de ambos enlaces: 12 noviembre 2012].

2225. CANTALAPIEDRA EROSTARBE, Fernando, "Fue tanto breve quanto muy sutil. Los paratextos de La Celestina», eHumanista 19 (2011), 20-78.

Largo y detenido estudio de los materiales liminares de $L C$ en su orden de aparición e inclusión. Entre las ideas propuestas, el autor conjetura que el argumento general se haya escrito con frases extraídas de la $C C M$, rechaza que dicho argumento, junto con el "Síguese», sean obra de Rojas o de un segundo autor; se ocupa detalladamente de los grabados de la CCM de Burgos comparándolos con sus posibles modelos (los incunables de Terencio y Horacio de Grüninger) y relaciona la "Carta a un su amigo" con el prólogo de Hernán Núñez a las Trescientas de Mena y otros textos para mostrar cómo la primera cumple totalmente con las normas y los tópicos de los proemios. 
2226. CARMONA RUIZ, Fernando, "La cuestión iconográfica de la Celestina y el legado de Hans Weiditz», eHumanista 19 (2011), 79-112.

Tras un breve repaso de los estudios dedicados a la iconografía de algunas de las ediciones de $L C$ y subrayar la escasez de trabajos que han tratado del análisis iconográfico de las xilografías, el autor pasa a ocuparse detenidamente de las estupendas ilustraciones que acompañan a la traducción alemana de 1520 de la obra maestra española. Compara estas con las de la CCM de Burgos con el objetivo de destacar semejanzas y diferencias y resalta la estrecha relación entre texto e imagen.

2227. CORFIS, Ivy A., "Imagining Celestina», eHumanista 19 (2011), 113-136.

En el artículo se subraya la importancia de la imaginación y de la memoria en la obra tanto para los personajes mismos como para los lectores. Estos dos componentes tendrían por lo tanto un papel nada indiferente para una justa interpretación y recepción de $L C$.

2228. DONOSO RODRÍGUEZ, Miguel, "Mujer y misoginia en tres textos medievales españoles», Taller de Letras 43 (2008), 121-130.

Tomando el hilo de una serie de televisión chilena misógina, el autor presenta algunas reflexiones al respecto y demuestra como este sentimiento anti-femenino, de proveniencia bíblica y grecolatina, se encontraba ya en obras medievales castellanas como el Libro de buen amor, el Corbacho y LC.

2229. EALY, Nicholas, "Calisto's Narcissistic Visions: A Reexamination of Melibea's 'Ojos Verdes' in Celestina», eHumanista 21 (2012), 390-409.

El estudio se detiene en la descripción que hace Calisto de Melibea en el auto I y trata, en particular, de la singular referencia a los «ojos verdes» de su amada (véase, abajo, Garci-Gómez, que se ha ocupado del mismo tema). Según el autor, estos representarían una metáfora del deseo trascendental de Calisto que relacionaría al enamorado con el narcisismo de procedencia ovidiana presente en la obra y subrayaría la importancia de la mirada en el desarrollo de la trama.

2230. FERNÁNDEZ RIVERA, Enrique, "La caída de Calisto en las primeras ediciones ilustradas de La Celestina», eHumanista 19 (2011), 137-156.

El artículo analiza el grabado de la caída de Calisto en su primera aparición, es decir, en el ejemplar de la CCM de Burgos, y muestra la influencia que este ha tenido en las ediciones ilustradas de la obra de la primera mitad del siglo XVI. Probablemente los autores de la xilografía siguieron como modelo, voluntaria o involuntariamente, la representación iconográfica de la caída de Fortuna y la depositio Christi. 
2231. FERNÁNDEZ VALLADARES, Mercedes, «Biblioiconografía y literatura popular impresa: la ilustración de los pliegos sueltos burgaleses (o de babuines y estampas celestinescas)», eHumanista 21 (2012), 87-131.

El artículo estudia la ilustración de los pliegos sueltos burgaleses de los siglos XV y XVI. A través del análisis de este corpus se ha determinado qué tipo de ilustraciones se preferían para los romances o textos similares («escenas» o "historias») frente a obras de contenido festivo, dialógico y teatral (figuritas "factótum»). En la última parte trata del posible origen de algunas escenas que se encuentran en las ediciones más antiguas de historias caballerescas breves y al mismo tiempo se enfoca en las estampas de la CCM burgalesa, reconstruyendo su trayectoria y conjeturando sobre el posible procedimiento técnico que se siguió en el diseño de algunos elementos de sus grabados.

2232. GALARRETA-AIMA, Diana, «El tiempo de La Celestina: el deseo, el placer y el egoísmo como motivos de interpretación de la obra», Celestinesca 35 (2011), 43-66.

El artículo trata de la importancia del tiempo en $L C$ y se ocupa, en particular, de dos temas directamente relacionados con los personajes: el tiempo como tirano que los oprime y atrasa la realización de sus deseos; y el tiempo subjetivo de cada uno de ellos. El análisis de esta conciencia temporal nos permitiría apreciar los cambios que se estaban desarrollando en la sociedad castellana a finales de la Edad Media.

2233. GARCI-GÓMEZ, Miguel, «Los ojos verdes de Melibea. Su retrato en el marco europeo», en línea (http://mgarci.aas.duke.edu/cibertextos/ROJAS-FD/CELESTINA/; fecha de consulta: 8 septiembre 2012).

Artículo que se enfoca en los «ojos verdes» de Melibea, detalle original (en cuanto al color) que no parece haber interesado a la crítica hasta tiempos recientes (véase, arriba, Ealy, que trata del mismo argumento). El autor recoge toda una serie de ejemplos literarios, desde Homero hasta nuestros tiempos, teniendo en consideración también a la música, con el objetivo de demostrar cómo, en España y Latinoamérica, se ha ido formando este tópico de la belleza de los «ojos verdes».

2234. GERLI, E. Michael, "Agora que voy sola’: Celestina, Magic, and the Disenchanted World», eHumanista 19 (2011), 157-171.

En contra de lo que ha argüido Russell y la mayoría de la crítica posterior, Gerli piensa que la magia no tiene ningún papel importante en $L C$. En realidad en la obra habría indicios suficientes como para negar la efectividad de cualquier práctica sobrenatural y los personajes (la alcahueta in primis) serían conscientes de la inutilidad e ineficacia de conjuros, amuletos, hechizos, etc. 
2235. GUARDIOLA-GRIFFITHS, Cristina. "Medieval Mean Girls: On Sexual Rivalry and the Uses of Cosmetics in La Celestina», eHumanista 19 (2011), 172-192.

El estudio se centra en la rivalidad entre los personajes femeninos de $L C$ y, sobre todo, en sus conocimientos acerca de los cosméticos y el uso que hacen de estos. En particular, la autora, tras presentar una breve historia del arte del maquillaje, analiza los tratamientos de belleza que cita Areúsa en la crítica que hace de Melibea en el auto IX.

2236. GUTWIRTH, Eleazar, «El polvo de la oveja: paremiología, marco y posterioridad», eHumanista 14 (2010), 105-126.

Detenido examen del refrán «el polvo de la oveja, alcohol es para el lobo». Se estudia, en particular, tanto su presencia, marco, interpretación y utilización en diferentes obras, entre las que se cuenta $L C$, como su posible génesis y poligénesis en tradiciones distintas.

2237. HEUSCH, Carlos, "Faire chère lie dans une valée de larmes: le banquet carnavalesque de Célestine», en Etre à table au Moyen Âge, ed. Nelly Labère (Madrid: Collection de la Casa de Velázquez, 2010), 163-175.

El trabajo se enfoca en el tema de la comida en LC mostrando cómo este es un elemento característico de las clases más bajas mientras que en las altas de los nobles, como en los protagonistas de la novela sentimental, les importaría solamente el amor. Se estudia detenidamente el banquete del auto IX analizando su dimensión carnavalesca (donde reina la lógica del exceso y la desmesura), el papel de Celestina (ninfómana, comensal y amante del vino) y la parodia del convivium ciceroniano (en lugar de buscar la verdad y el bien, en el banquete los protagonistas estarían más bien interesados en el vicio y el mal). Por último, se hace referencia a "l'esprit de la faim», como la llama el autor, es decir, a esta visión del mundo que contrapone los hambrientos a los sacios y presenta la lucha para sobrevivir, ingrediente que se desarrollará todavía más en la picaresca de las décadas siguientes.

2238. IGLESIAS, Yolanda, "La prostitución en La Celestina: estudio histórico-literario", eHumanista 19 (2011), 193-208.

En el trabajo se estudia la prostitución desde una perspectiva histórico-literaria. Se analiza primero su presencia en la obra maestra española, luego se muestra cómo su autor se adhiere a la realidad social de la época retratando fielmente lo que pasaba en sus tiempos y, por último, se presentan algunas consideraciones/conclusiones acerca de su posible punto de vista en relación con este fenómeno social. 
2239. KESEN, Nelly, "El tratamiento del espacio urbano en La Celestina», en IX Congreso Argentino de Hispanistas (27 al 30 de abril de 2010, La Plata, Argentina), Universidad Nacional de La Plata. Facultad de Humanidades y Ciencias de la Educación. Centro de Estudios de Teoría y Crítica Literaria, 2010. Actas publicadas en línea (http://ixcah.fahce. unlp.edu.ar/actas; fecha de consulta: 20 octubre 2012).

En el estudio se analiza el espacio urbano de $L C$ a partir de las descripciones que dan los personajes del ambiente y los edificios que los rodean. Al mismo tiempo, siguiendo de cerca a los planteamientos de Paul Zumthor, se intenta determinar qué relación existe entre esta ciudad imaginaria e imaginada y la sociedad representada.

2240. LIZABE, Gladys, "El concepto de 'familia' en La Celestina», en IX Congreso Argentino de Hispanistas (27 al 30 de abril de 2010, La Plata, Argentina), Universidad Nacional de La Plata. Facultad de Humanidades y Ciencias de la Educación. Centro de Estudios de Teoría y Crítica Literaria, 2010. Actas publicadas en línea (http://ixcah.fahce.unlp.edu. ar/actas; fecha de consulta: 20 octubre 2012).

El trabajo analiza las diferentes tipologías de «familia» que se encuentran en la obra maestra española centrándose, en particular, en la «familia» prototípica, compuesta por Pleberio, Alisa y Melibea, y la híbrida, es decir, la de Celestina y Pármeno.

2241. LÓPEZ-RÍOS, Santiago, "Celestina habla gallego: La Comedia dos tolos amores de Calisto e Melibea de Eduardo Alonso", eHumanista 19 (2011), 209-233.

El estudio se centra en el análisis de la primera traducción (muy libre) de $L C$ al gallego, todavía inédita, y de su adaptación escénica y consecuente representación con el título de A Celestina. Comedia dos tolos amores de Calisto e Melibea. Ambas tareas se deben a Eduardo Alonso. A continuación, se incluye una entrevista con el director y traductor.

2242. LÓPEZ-RÍOS, Santiago, «'Señor, por holgar con el cordón no querrás gozar de Melibea': la parodia del culto a las reliquias en la Celestina», MLN 127 (2012), 190-207.

El artículo analiza detenidamente el simbolismo del cordón de Melibea y señala cómo, a través de este, se presentaría una parodia del culto cristiano a las reliquias. Al mismo tiempo subraya la importancia de la hagiografía en la composición de $L C$.

2243. MINIC-VIDOVIC, Ranka. "Los elogios de Leriano y la parodia de Fernando de Rojas: una lectura sociológica», eHumanista 19 (2011), 234-259. 
Tras ofrecer un análisis de la literatura amorosa cortesana y del papel social y la condición de la mujer en la Edad Media, el artículo se centra en el estudio de los personajes femeninos en la Cárcel de amor y $L C$.

2244. MONTERO, Ana Isabel, «A penetrable text? Illustration and transgression in the 1499(?) edition of Celestina», Word \& Image 21.1 (JanMar 2005), 41-55.

La estudiosa propone una lectura de los grabados de la CCM de Burgos independientemente del texto. Se centra, ante todo, en el simbolismo erótico ínsito en la acción de pasar a través de unas puertas (acción representada en la mayoría de los grabados). Estas entradas indicarían, en contra de los que han argüido que simplemente servían de marco divisorio entre dos escenas distintas y consecutivas, el punto de encuentro entre el mundo interior (cerrado, patriarcal, en defensa de la virginidad de Melibea) y exterior (representado por la alcahueta y la subversión de aquel).

2245. PAOLINI, Devid, "Celestina: Documento bibliográfico (suplemento número 33)», Celestinesca 35 (2011), 193-206.

En el último suplemento bibliográfico se han agregado más de 50 entradas que desde 1985 suman ya 2220 .

2246. PAOLINI, Devid, "Madonna Gentile Feltria de Campofregoso, Alphonso Hordognez y la traducción italiana de La Celestina», eHumanista 19 (2011), 260-295.

Se traza, en este trabajo, una biografía de Madonna Gentile de Campofregoso, hija ilegítima de Federico de Montefeltro, Duque de Urbino, a quien Alphonso Hordognez dedicó la traducción italiana de LC. También se especula sobre cuándo y cómo los dos se conocieron, en qué ambientes se movieron y cuándo se comisionó la traducción al italiano de la obra maestra española.

2247. PAOLINI, Devid, "Ediciones de La Celestina anteriores al siglo XIX en la Biblioteca Nacional de España», Revista de Literatura Medieval XXII (2010), 351-359.

Un listado de todas las ediciones de LC que se conservan en la Biblioteca Nacional de España. En un apéndice al final se ofrece una puesta al día de algunas entradas de Penney (The Book Called "Celestina" in the Library of the Hispanic Society of America).

2248. PAOLINI, Devid, «Sobre un tópico equivocado (las representaciones de las comedias de Plauto y Terencio en España a finales del siglo xv) y Celestina», Celestinesca 35 (2011), 67-84. 
No obstante se siga repitiendo que las comedias de Plauto y Terencio se representaban en España a finales del siglo Xv, no hay ni una sola evidencia histórica que lo pruebe. En el artículo, tras comparar la tradición dramática italiana con la castellana, se intenta explicar cómo y cuándo pudo nacer este tópico equivocado. Al mismo tiempo se subraya cómo la ausencia de tales espectáculos complica todavía más la cuestión de la génesis de $L C$, obra que se inscribe en el género dramático y tiene como modelo, entre otros, la comedia romana.

2249. PÉREZ ÁlVAREZ, Víctor, «El reloj y el tiempo en la Castilla bajomedieval a través de la literatura», en Castilla y el mundo feudal. Homenaje al Profesor Julio Valdeón (eds. coord. M. I. del Val Valdivieso - P. Martínez Sopena - colab. D. Pelaz Flores), Valladolid, Junta de Castilla y León-Universidad de Valladolid, vol. 3, 2009, 494-502.

Breve estudio que se centra en el cambio de la concepción y percepción del tiempo en la sociedad castellana del siglo XV a través del análisis de las referencias al «reloj» en dos poemas de Juan de Mena y en $L C$.

2250. PÉREZ DE LEÓN, Vicente, «La excepcionalidad de la magia de los vínculos y el desafío de las clases sociales en La Celestina», Dicenda. Cuadernos de Filología Hispánica 29 (2011), 265-287.

El estudio propone una lectura/interpretación de la sociedad dibujada en $L C$ a través de los escritos de Giordano Bruno, en particular, los que tratan de la magia de los vínculos del Eros. Este acercamiento permitiría rastrear en la obra la presencia de estructuras comunitarias paralelas y, al mismo tiempo, la alegoría de la rémora o Equeneis.

2251. PUERTO MORO, Laura, "Más sobre el humor en la Tragicomedia. De personajes celestinescos y tipos cómicos tradicionales, entre otras cuestiones", eHumanista 19 (2011), 296-316.

El estudio se ocupa del humor centrándose, en particular, en los personajes que más caracterización han recibido en el cambio de CCM a TCM. La ampliación, que puede muy bien considerarse un "entremés» añadido, se habría llevado a cabo no tanto para alargar el plazo de amor entre los dos jóvenes, sino con el objetivo de cumplir con las expectativas de un público lector que pedía más diversión y entretenimiento en la obra. Se señala, además, la influencia que pudieron tener unos tipos cómicos tradicionales como, por ejemplo, los que se encuentran en la «literatura de comadres».

2252. ROJAS, Fernando de, (y "antiguo autor»). La Celestina. Tragicomedia de Calisto y Melibea. Edición y estudio de Francisco J. Lobera y Guillermo Serés, Paloma Díaz-Mas, Carlos Mota, e Íñigo Ruiz Arzálluz, y Francisco Rico. Biblioteca Clásica de la Real Academia Española, 
vol. 18. Madrid: Real Academia Española, 2011. 1112pp. ISBN 97884-8109-986-7

Es esta una reimpresión de la edición crítica del año 2000 con una puesta al día de los estudios introductorios (ya reseñados por JTS en el suplemento bibliográfico de Celestinesca 25 [2001], núms. 1362, 1374, 1398 y 1404), las notas complementarias y del aparato de variantes.

2253. ROJAS, Fernando de, Celestina: Calisto és Melibea tragikomédiája, trad. de Szőnyi Ferenc, Budapest, Eötvös J. Kvk., 2010. 207pp.

Nueva edición de la traducción al húngaro de $L C$ (el mismo traductor, junto con Károlyi Sándor, había publicado ya en 1979 una traducción de la obra como puede verse en el catálogo en línea de la Biblioteca Nacional de Hungría, http://nektar1.oszk.hu/librivision_eng.html; fecha de consulta: 12 noviembre 2012).

2254. ŠABEC, Maja, «El papel de la enfermedad de amor en la Tragicomedia de Calisto y Melibea», Tropelías. Revista de Teoría de la Literatura y Literatura Comparada 18 (2012), 308-325.

En el estudio se analiza el amor entre Calisto y Melibea desde el punto de vista médico, es decir, como enfermedad de amor, causa primaria tanto del enredo como del fin trágico de la pareja de amantes

2255. SAGUAR, Amaranta, "Influencia de la hipérbole sacroprofana bíblica sobre la interpretación y la estructura de Celestina», en La tinta en la clepsidra: Fuentes, historia y tradición en la literatura hispánica, eds. S. Boadas, et al., PPU, 15-24.

En el estudio se ofrece un análisis de las diferentes funciones que tiene la hipérbole sacroprofana para una correcta interpretación de $L C$ y se muestra la influencia que tiene en la construcción de determinados episodios en la obra (como el diálogo entre la alcahueta y Melibea y el suicidio final de esta con consecuente lamento de su padre Pleberio).

2256. SÁNCHEZ FERNÁNDEZ, Juan A., La tesitura de "La Celestina» (una aproximación), Praga: Universidad Carolina de Praga-Editorial Karolinum, 2012. 222 pp. ISBN 978-80-246-1918-7

Monografía general que tiene como objetivo ofrecer una introducción al estudio de $L C$ y a los principales problemas histórico-literarios que la obra presenta (autoría, fuentes, interpretación, magia, prostitución y sociedad).

2257. SÁNCHEZ SÁNCHEZ-SERRANO, Antonio y Remedios PRIETO DE LA IGLESIA, «'Auctor', 'Autor' y otros problemas semánticos concernientes a la autoría, gestación y ediciones de la Celestina», Celestinesca 35 (2011), 85-136. 
Detenido análisis semántico de los términos «autor» (quien prepara un texto, ya sea suyo o de otros, para la publicación), «auctor» (quien escribe una obra y/o posee un derecho sobre ella), «imprimir» y sus derivados, que tiene implicaciones directas en la autoría de $L C$, su gestación y la fecha de sus primeras ediciones.

2258. SNOW, Joseph T., "Darkness, Death and Despair in Celestina: An Essay», eHumanista 19 (2011), 317-327.

El artículo presenta un análisis detenido de algunos pasajes de la obra con el objetivo de demostrar cómo la obscuridad, la muerte y la desesperación tienen un papel muy significativo en el desarrollo de la trama de $L C$.

2259. SNOW, Joseph T., "Have You (Over) Heard? Another Dramatic Technique In Celestina», en La pluma es lengua del alma: Ensayos en honor de E. Michael Gerli. Ed. José Manuel Hidalgo. Newark (DE), Juan de la Cuesta, 2011, 343-366.

A través de una lectura minuciosa de la obra, en el artículo se llama la atención sobre los posibles personajes «mudos» e invisibles de $L C$, es decir, aquellos cuya presencia se puede imaginar y argüir en diferentes pasajes y situaciones sin que tuvieran, en aquel mismo instante, ningún papel efectivo y activo en ella.

2260. TURNER III, Robert L. "Wresting the Scriptures unto Destruction: biblical use and misuse in The Celestina». Bulletin of Spanish Studies 87.7 (2010), 887-896.

En el artículo se analizan las referencias bíblicas y religiosas de $L C$ cuyo sentido originario se ha alterado y adaptado a un nuevo contexto. A través del análisis de estas se intenta demostrar cómo la obra maestra española no puede considerarse un texto didáctico cristiano sino, al contrario, una obra subversiva.

2261. UGARTE, Xus, «Ensayo de descalificaciones y maldiciones personales en Celestina y en la traducción catalana de Antoni Bulbena», Celestinesca 35 (2011), 137-158.

El artículo analiza los adjetivos que se emplean en la obra para atacar o despreciar a un personaje así como las expresiones amenazadoras y maldicientes. A continuación se estudia cómo este corpus se ha vertido al catalán en la traducción de Antoni Bulbena i Tosell.

2262. VASVÁRI, Louise $\mathrm{O}$. "¡ $¡ \mathrm{O}$, qué comedor de huevos assados era su marido!': Further Glosses on the Vocaburlario of Celestina, IV", en La pluma es lengua del alma: Ensayos en honor de E. Michael Gerli. Ed. José Manuel Hidalgo. Newark (DE), Juan de la Cuesta, 2011, 367-386. 
Cuarta aportación al vocaburlario de $L C$. Tras ocuparse de los términos «landrecillo» y "cola de alacrán» en el famoso diálogo entre Pármeno y la alcahueta en el acto I (Celestinesca 33 [2009], núm. 2053), del «dolor de muelas» de Calisto (ibid., núm. 2054) y de la acepción de «desplumar» (Celestinesca 34 [2010], núm. 2162), la estudiosa analiza aquí la tan controvertida expresión de Pármeno en el auto I: « $¡$, qué comedor de huevos assados!».

2263. WEISSBERGER, Barbara F., "The Genesis of Paula Rego's A Casa de Celestina», en La pluma es lengua del alma: Ensayos en honor de E. Michael Gerli. Ed. José Manuel Hidalgo. Newark (DE), Juan de la Cuesta, 2011, 407-432.

El artículo trata de la pintora portuguesa Paula Rego y de cómo ha interpretado y se ha relacionado con $L C$ y, en particular, con el personaje de la medianera, en su obra pictórica titulada A Casa de Celestina. Tras un análisis del cuadro, la estudiosa señala cómo este representa el estadio más alto de una crítica feminista en contra de una sociedad represiva que la artista había empezado ya en otras obras suyas anteriores. Por último, dedica un apartado al posible papel de Celestina como experta en el proceso de abortar.

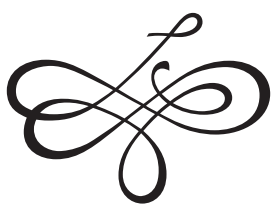


